\title{
Los efectos secundarios del electroque en la poesía de Anne Sexton: «Music Swims Back to Me» y su traducción al español
}

\section{Side Effects of electroshock in Anne Sexton's Poetry: "Music Swims Back to Me" and its Spanish Translation}

\begin{abstract}
VÍCTOR ANGUITA MARTíNEZ victoranguitamartinez@gmail.com Universidad de Córdoba

Fecha de recepción: 15 de octubre de 2018

Fecha de aceptación: 4 de febrero de 2019

Resumen: Anne Sexton (1924-1974) es una de las figuras más representativas del movimiento confesional poético desarrollado en los Estados Unidos durante el siglo XX. Vencedora del premio Pulitzer de poesía en 1970, profesora en la Universidad de Boston y doctora honoris causa en tres ocasiones, la joven poeta vio su vida troncada por la inestabilidad emocional y la enfermedad mental que la obligaron a pasar numerosos, aunque breves, ingresos en instituciones siquiátricas. Fruto de esta experiencia nace su primer poemario, To Bedman and Part Way Back (1960), que incluye el poema "Music Swings Back to Me», donde narra su desorientación y confusión tras una sesión de electrochoque. Este poemario tuvo que esperar hasta 2013 para verse publicado en español como parte de la antología Poesía completa de Ediciones Linteo traducido por José Luis Reina Palazón. Nuestro estudio pretende reflexionar acerca de los límites teóricos de la literatura escrita sobre el trasvase interlingüístico de obras en verso, acercarnos a la figura de la poeta, adentrarnos en los entresijos del texto para analizar la traducción, localizar dificultades, errores y aciertos de traducción y proponer una traducción alternativa que intente brindar soluciones a la problemática traductora resultante de la complejidad estilística del poema original.
\end{abstract}

Palabras clave: Anne Sexton, traducción poética, poesía confesional, electrochoque, enfermedad mental.

Abstract: Anne Sexton (1924-1974) is one of the most representative leading figures of the confessional poetry developed in the United States during the XX century. Pulitzer Prize-Winner in 1970, lecturer at the Boston University and doctorate honoris causa in three times, this young poet's life was 
truncated by emotional instability and mental illness that forced her to be admitted, numerously and for a short period of time, in different psychiatric institutions. Fruit of this experience was born her first book of poems, To Bedlam and Part Way Back (1960), in which "Music Swims Back to Me," is included, where disorientation and confusion after an electroshock session is narrated. Nevertheless, these poems had to wait untill 2013 to be published in Spanish language as part of Poesía completa, anthology edited by Ediciones Linteo and translated by José Luis Reina Palazón. Our study aims to reflect on the theoretical limits in poetry translation, to serve as approach to the poet's life in order to get into the intricacies of the text to analyze the Spanish translation and locate translating difficulties, mistakes and wise decisions. Finally, an alternative translation that attempts to provide solutions to the translation problems resulting from the stylistic complexity of the original poem will be proposed.

Keywords: Anne Sexton, Poetry Translation, Confessional Poetry, Electroshock, Mental Illness.

\section{INTRODUCCIÓN}

Afrontar la traducción de un texto literario no es, bajo ningún concepto, una tarea sencilla. El poema, como unidad textual con sentido completo, ha sido analizado por los estudiosos de Traducción, en líneas generales, desde su contenido formal. Esto se debe a que la poesía clásica, tan ligada las estructuras macrotextuales propias, a los esquemas métricos y patrones rítmicos, otorgaba una mayor importancia a la forma si lo comparamos con la poesía contemporánea. A su vez, la superposición del plano fonético se suma en la lucha por obstaculizar la labor del traductor, puesto que «cuanto más vinculado esté el mensaje de la obra original a la materia fónica de su lengua, tanto mayor será la dificultad del traductor para expresar en la suya ese mensaje» (Yebra, 1994: 20). Por ello, muchos, como Jakobson (2000) han sido los detractores del trasvase del texto poético.

Sin embargo, la forma de crear poesía ha ido evolucionando y adaptándose a las nuevas formas de consumo editorial. Las últimas tendencias en poesía abogan por la creación de un ritmo propio sin encofrarse dentro de una estructura fija y recurriendo a las imágenes y proyecciones de las palabras en el lector. En otras palabras, la poesía más actual se fundamenta, en mayor medida que en la anterior, en factores como la ambigüedad léxica, la polisemia, la creación metafórica, juegos de palabras, dobles sentidos y todo un amplio etcétera de contenidos 
pragmáticos que configuran el nacimiento del poema dentro de la pragmática perteneciente a la cultura que lo acuna en su nacimiento.

Al cumplir su función, el traductor deberá enfrentarse a la ruptura de las estructuras sintácticas convencionales, la semiótica trasmutada en metáforas, los juegos de palabras y fallos pragmáticos — sobre los que se erigen las dosis de humor del texto, entre otros-, así como las variedades diatópicas, diastráticas o diafásicas; en definitiva, a todas las asimetrías que presenten los pares de lengua que confrontemos.

Como venimos diciendo, la teoría de la traducción ha reflexionado largo y tendido sobre estos escollos, poniendo el punto de mira en el aspecto más lingüístico del proceso traductor y dejando atrás lo que consideramos más importante: el acto pragmático-comunicativo que el autor establece con su lector. $Y$ es que, cuando traducimos, acercamos culturas e importamos cánones que ayudan a la evolución del sistema literario que los recibe. Muchos de los grandes literatos lo son, sin lugar a dudas, gracias a las traducciones de sus obras. Es por ello oportuno poner en el punto de mira la necesidad de una aproximación teórica que considere y fundamente la génesis de la traducción, entendida como proceso y producto, del texto poético. Conviene destacar los trabajos teóricos y empíricos que apoyan este enfoque comunicativo de Samaniego (1996, 2002 y 2011) y Ramírez (2009), que pese a estar centrados en el trasvase del contenido metafórico del poema, sus aportaciones se pueden extender a la traducción de poesía en su conjunto «puesto que en el lenguaje poético se incluye la metáfora que el autor utiliza como uno más de los múltiples recursos para expresar sus ideas» $(2009 ; 115)$

[...] el TM debe reunir dos requisitos fundamentales: ser comunicativamente equivalente al $\mathrm{TO}$, es decir, recoger en lo posible el programa conceptual de su autor y, a la vez, ser aceptable en la cultura meta. Debido al carácter intercultural de la comunicación, la interacción de ambos requisitos crea a menudo contradicciones (incompatibilidad) que deben ser resueltas por el traductor con el mínimo de pérdidas y el máximo de ganancias para los comunicantes (íbid).

De igual modo, el traductor que emprende la senda de la traducción de un texto de esta índole no encuentra grandes apoyos metodológicos en la Traductología, pues no son muchos los investigadores que dedican sus estudios al desarrollo de estrategias y material didáctico en formación ${ }^{1}$ de

\footnotetext{
${ }^{1}$ En su artículo «La didáctica de la traducción poética en el EESS» (2013), Jesús Berlotto ayuda a comprender mejor la situación de la enseñanza de la traducción poética en la universidad española y una reflexión sobre las didácticas recurrentes para la formación de traductores, véase
} 
traductores de esta especialidad. En otras palabras, existen incontables publicaciones sobre literatura comparada, donde el objetivo del trabajo no es otro que el cotejo y análisis traductológico de un producto editorial ya en el mercado $y$, por el contrario, pocas son las monografías dedicadas al aprendizaje de estrategias para la traducción de poemas. A este respecto, la propuesta de Soto (2014), pretende servir como herramienta para la adquisición de competencias traductoras para un campo tan específico de la traducción literaria, apostando por la traducción-recreación en términos de Etkind.

En su ya canónica obra Un art en crise: essai de poétique de la traduction poétique (1982) Etkind propone una división en seis modalidades que consideramos la más inclusiva de las existentes: el abanico de posibilidades gira en torno al contenido del poema frente a la forma. Este elenco de posibilidades está compuesto por traducción-información, traducción-interpretación, traducción-alusión, traducción-aproximación, traducción-imitación y traducción-recreación. Coincidimos con Etkind, aunque de una forma no tan categórica, en que la modalidad más acertada de traducción es la traducción-recreación, si bien no la traducción verdadera, porque como apunta Hurtado (2004: 66) «ciertos tipos de poesía visual tienen características muy peculiares, y pueden llegar a presentar problemas de traducción de difícil resolución».

Una vez que nos hemos decantado por una modalidad de traducción, solo nos falta proponer un planteamiento de trabajo. Consideramos pertinente la propuesta de Silvestre (2008: 132), quien propone dividir un encargo de traducción en los siguientes pasos:

1. Realizar un análisis filológico exhaustivo de los planos léxico y gramatical.

2. Reanalizar las palabras que componen el texto y desmenuzar el universo semántico en los dos idiomas.

3. Conocer las asociaciones mentales que el texto pueda provocar en el lector nativo para trasvasar en la medida posible dichas asociaciones al público meta.

4. Por último, realizar un análisis de lo connotativo, yendo de lo general a lo particular y dejando atrás las interpretaciones personales.

Podemos observar que se tienen en cuenta, por un lado, los aspectos formales del poema, y por otro, lo semiótico del contenido poético y metafórico que se encuentra intrínsecamente arraigado en la cultura que observa y descodifica. Por otro lado, el revisor, encargado de desandar el camino del traductor en la confrontación original-traducción para formular evaluaciones y correcciones con el fin de disminuir la pérdida inevitable de la 
traslación interlingüística del texto en verso, deberá tener en cuenta todos los factores que mencionamos al comienzo de este estudio.

\section{OBjetivos y Metodología}

Nuestro estudio pretende someter a análisis un poema de Anne Sexton titulado «Music Swims Back to Me», recogido en To Bedlam and Part Way Back (1960). Pese a ser publicado en 1960, como narra la biografía oficial de Anne Sexton, el poema lo escribió y lo compartió con Maxime Kumin en septiembre de 1957 sin apenas alteraciones respecto a la primera versión publicada del mismo (Middlebrook, 1998: 90-91). La versión en español tuvo que esperar hasta el 2013, fecha en la que Linteo Poesía, a manos José Luis Reina Palazón, Premio Nacional de Traducción en 2000, decidió verter al español The Complete Poems (1999).

Nos acercaremos a la figura de la poeta a través de su vida y la evolución del tratamiento de estimulación térmica, leitmotiv del poema en cuestión para cumplir con el estudio filológico del original, llevar a cabo un análisis lingüístico del TO y el TM, para desarrollar un estudio comparativo entre ambos dividido en tres planos: léxico-semántico, verbal y sintáctico y pragmático (para el estudio de la carga metafórica), con el que trataremos de arrojar luz y dar respuestas a las siguientes preguntas en las próximas páginas: ¿De qué estrategias se ha servido el traductor y cuáles son, de haberlas, las limitaciones formales que determinan la elección de una u otra? ¿Presenta el texto alteraciones o errores que alejan al lector meta del original? ¿Es necesaria una retraducción del poema?

\section{ANNE SEXTON Y EL MOVIMIENTO CONFESIONAL EN POESÍA}

Hoy no cabe la menor duda de que «el lenguaje que utilizamos es portador de huellas y vidas previas. Cada palabra que elegimos trae consigo la de otras tantas cargadas igualmente de historias prodigiosas que hay que liberar» (Vidal, 2005:15); y hay experiencias vitales tan intensas y con tan abundantes dosis de realidad que configuran la explosión literaria de quienes las cuentan. Al hacer de la poesía su herramienta de liberación en la lucha contra la enfermedad mental y el declive emocional, Anne Sexton (19281974), máximo exponente, junto a Robert Lowell y Silvia Plath, del movimiento confesional poético estadounidense, es un claro ejemplo de lo que venimos diciendo.

Diagnosticada de trastorno bipolar tras una depresión postparto y con tendencias suicidas, Anne Sexton comienza a escribir por recomendación de

Hikma 18 (1) (2019), 211 - 230 
su terapeuta, el Dr. Orne, como complemento a las sesiones grabadas en las que fundamentó su tratamiento. Pretendía con ello paliar sus problemas de autoestima y memoria, consecuencias de las presiones sociales imperantes sobre la figura de la mujer en los Estados Unidos a mediados del siglo pasado. El mismo Dr. Orne así lo confirma en el prólogo de Anne Sexton: una biografía (1998), escrita por Diane Middlebrook y basada en las cintas grabadas de las terapias cedidas por el propio psiquiatra y la primogénita de la poeta, Linda Sexton:

Se sentía impotente e incapacitada para hacer tanto de esposa como de madre y estaba dolida porque la habían privado de sus hijas, pese a reconocer que, en realidad, no era capaz de ocuparse de ellas. De hecho, las amaba tiernamente y también a su familia, pero no estaba en condiciones de afrontar la función que estaba llamada a desempeñar. Por mucho que intentara estar a la altura de la imagen que se tenía en los años cincuenta de lo que era ser una buena esposa y una buena madre, el esfuerzo estaba fuera de su alcance (1998: 7).

Sin embargo, lo que empezaron siendo unas anotaciones acabaron convirtiéndose en poemas a través de los cuales Anne Sexton conseguía canalizar sus emociones. Poco después, comenzó a asistir al taller literario de John Holmes donde conoció a Maxime Kumin, con quien mantuvo una amistad profunda y gracias al cual aprendió a pulir su estilo y alcanzar un gran nivel como poeta. A través de su obra, nos acerca a la sintomatología del trastorno bipolar que padecía y sus intentos de suicidio, la relación maternofilial, la menstruación o acercamientos religiosos. Estos temas, considerados tabúes o no aptos para el canon poético del marco histórico-literario en el que desarrolló su poesía, fueron recogidos bajo un movimiento denominado confesional en el que

$$
\begin{aligned}
& \text { El autor tiene la capacidad de moldear sus confesiones por escrito } \\
& \text { y ofrecerlas a la audiencia después de haber sido construidas en } \\
& \text { función de lo que el poeta quiere desvelar, en un proceso consciente } \\
& \text { de creación, de tal manera que el material personal que pueda } \\
& \text { contener el texto es siempre ordenado y dispuesto según la } \\
& \text { voluntad del autor, sin la interferencia de agentes extraños que } \\
& \text { hagan juicios de valor o que formulen veredictos sobre la estabilidad } \\
& \text { emocional de la persona [...] (Martín, 2003:177). }
\end{aligned}
$$

Anne Sexton consiguió en poco tiempo que la remuneración de sus recitales alcanzara cuotas desorbitadas, convirtiéndose en una de las poetas mejor pagadas del siglo XX; también recibió grandes reconocimientos: impartió clases en la Universidad de Boston, venció el premio Pulitzer en 1967 y la nombraron doctora honoris causa por la Tufts University en 1970, por la Fairfield University en 1972 y por el Regis College en 1973. Todo el éxito 
profesional no consiguió que se sobrepusiera a su enfermedad mental y tras varios intentos fallidos de suicidio, consiguió quitarse la vida encerrándose en el garaje de su casa con el motor del coche encendido en 1974.

\section{ENFERMEDAD MENTAL: POESÍA Y ELECTROCHOQUE}

En 1960 Houghton Mifflin publica To Bedlam and Part Way Back, primera obra de Anne Sexton centrada en su cuadro clínico y en el tratamiento de su estado mental. En ella se recoge un poema titulado «Music Swims Back to Me» en el que describe con precisión los efectos del electrochoque sobre el cuerpo, la memoria y el sentido de la orientación. Para comprender mejor el universo al que nos quiere acercar la autora necesitamos, en primer lugar, ampliar conocimientos sobre este tratamiento tan mitificado y recurrente en la ficción.

Con el fin de elevar la temperatura corporal hasta llegar a la convulsión para aplanar los síntomas de muchas de las enfermedades mentales que incluyen delirios, como la esquizofrenia, los psiquiatras se han valido a lo largo de la historia de diversos métodos. En un principio, se inyectaba en los pacientes, de forma controlada y con un límite de sesiones establecido, una variación del virus de la malaria (pirototerapia malárica), que fue sustituido por el Cardiazol (cardiazolterapia) y después por insulina (insulinoterapia) hasta inducir al alienado a un estado de hipertermia. Inspirado en los tratamientos anteriores, a principios del siglo XX, Ugo Cerletti buscó la forma de sustituir los estímulos químicos por eléctricos. Fue en 1938 cuando él y Luigi Bini realizaron en Roma la primera sesión de electrochoque a un paciente; ante los resultados positivos, su método se difundió por todo el mundo. Max Fink, en su obra Electroshock: Restoring the Mind (1999), recoge tanto la fundamentación científica del método del psiquiatra italiano y los efectos colaterales de su aplicación, como otras cuestiones históricas y evolutivas del mismo. Expone que, debido a que los pacientes con ataques epilépticos presentan un mayor número de células gliales (encargadas de apoyar a las neuronas en el desarrollo continuo de las funciones corporales) y aquellos esquizofrénicos un número inferior a la media, se llegó a la conclusión de que inducir ataques epilépticos podría ayudar a regular y calmar los síntomas del paciente. A pesar del éxito aparente en las primeras intervenciones, en sus orígenes el electrochoque traía consigo efectos secundarios irreparables: pérdida de memoria, fracturación espinal, pérdida de la orientación, paro cardíaco y asfixia.

Estudios posteriores demostraron que se debía a la falta de oxigenación y anestesia durante el proceso. Los pacientes sometidos a electrochoque se quejaban de la pérdida de recuerdos, salvo aquellos hechos 
con los que establecían un vínculo afectivo estrecho o los que se repetían en continuidad. Esta pérdida de memoria podría deberse al efecto de los fármacos y a su suministro erróneo. La monitorización del paciente ha reducido el riesgo del procedimiento que incluso se puede aplicar en embarazadas durante el primer y último trimestre de gestación. Sin embargo, los efectos sobre el cerebro son inevitables, aunque hoy en día apenas sean perceptibles. Todo ello queda recogido y reflejado poema que sigue:

\section{Music Swims Back to Me}

Wait Mister. Which way is home? They turned the light out

And the dark is moving in the corner. There are no sign posts in this room, Four ladies, over eighty,

In diapers every one of them.

La la la, Oh music swims back to me And I can feel the tune they played The night they left me

In this private institution on a hill.

Imagine it. A radio playing And everyone here was crazy. I liked it and danced in a circle.

Music pours over the sense And in a funny way

Music sees more than I.

I mean it remembers better;

Remembers the first night here.

It was the strangled cold of November;

Even the stars were strapped in the sky And that moon too bright

Forking through the bars to stick me With a singing in the head. I have forgotten all the rest.

They lock me in this chair at eight a.m. And there are no signs to tell the way, Just the radio beating to itself And the song that remembers More than I. Oh, la la la, This music swims back to me. The night I came I danced a circle

Hikma 18 (1) (2019), 211 - 230 


\section{And was not afraid. Mister?}

A lo largo de esta composición, la poeta narra su breve estancia en un centro psiquiátrico «In this private institution on a hill». Pese a lo que se pueda inferir del poema, Anne Sexton no transcurrió largas temporadas en instituciones psiquiátricas ya que su terapeuta se percató de forma prematura de que no ayudaría en su tratamiento:

Por suerte me comentó casualmente que pasaba muchos ratos con dos pacientes esquizofrénicas, lo que me permitió comprobar que Anne tenía una tendencia a asumir los síntomas de aquellos con quienes se relacionaba normalmente. Teniendo en cuenta esta tendencia, procuré que no permaneciera en un ambiente hospitalario más tiempo del absolutamente imprescindible a fin de impedir que asimilara síntomas de otros pacientes (Orne en Middlebrook, 1998: 9).

En el suceder de metáforas e imágenes creadas en «Music Swims Back to Me», la bostoniana nos conduce con su danzar desorientado a través de la confusión que experimentó a consecuencia de la sesión de electrochoque a la que fue sometida. Como una niña perdida y asustada, llama la atención a un transeúnte para que le ayude a encontrar la ruta a casa tras la oscuridad del apagón de sus sentidos, "They turned the light out» y la ausencia de señalización, "There are no sign posts in this room», que la retienen encerrada junto a las ancianas en pañales, como si hubieran vuelto a la infancia para cerrar su ciclo vital, compartiendo la decadencia con la atmósfera que les rodea. La imagen de las señales la retoma en la última estrofa, haciendo hincapié en la pérdida del sentido de la orientación justo después de recibir una sesión de electrochoque: «They lock me to this chair at eight a.m. / And there are no signs to tell the way»). Esta idea de confusión y opacidad frente al espacio que la rodea se ve reforzada por otras imágenes, creando una atmósfera tétrica que provoca en el lector una experiencia sensorial análoga al pánico que ella sentía encerrada entre los barrotes de la institución: «It was the strangled cold of November; / Even the stars were strapped in the sky / And that moon to bright / Forking through the bars to stick me / With a singing in the head».

Como aliada contra el olvido, efecto secundario que comentábamos antes, muy característico tras ese tipo de sesiones, Anne Sexton gira todo el poema en torno a una radio que suena sin cesar e ignorada por el resto de pacientes. A lo largo de los versos, personifica la canción que sonaba justo en su ingreso, aquella que le hizo bailar en círculos —una vez más, una metáfora del estado de pérdida espacial en el que se encontraba- y que inunda sus sentidos para transportarla a la primera noche de encierro en la 
que no sentía miedo, ayudándola a recordar la tranquilidad de aquel día en el que disfrutó con la radio, bailó y fue valiente. Una canción que tiene un mayor control sobre la situación «And in a funny way / Music sees more than I. / I mean it remembers better;» y que contrasta con el recuerdo exclusivo del miedo de la poeta durante las noches de manicomio.

\section{4. «MUSIC SWIMS BACK TO ME» Y «LA MÚSICA VUELVE A Mİ»: CONFRONTACIÓN INTERLINGÜISTICA:}

Llegados a este punto, ya se ha expuesto toda la información relevante y necesaria para adentrarnos en la traducción de José Luis Reina Palazón. Nuestro análisis parte de la libertad de metro y rima del original, como se ha indicado en anteriores ocasiones. El traductor del poema no ve limitado su gama de posibilidades traductivas por las restricciones silábicas al no tener que ceñirse a un metro fijo ni a un patrón rítmico y acentual establecido. Valga como premisa que en todo momento se pretende encontrar posibles errores de traducción para intentar aportar mejoras allá donde sea necesario.

- Errores léxico-semánticos:

T.O: Wait, Mister. Which way is home?

T.M.: Espere, caballero. ¿Cuál es el camino a casa?

La elección del término caballero en lugar de señor alarga, de forma innecesaria, el verso en lengua española. El equivalente de Mister sería 'señor' y no 'caballero', cuya diferencia es análoga en la voz inglesa gentleman. En un intento por trasvasar la estructura formal del original, se pierde parte de la esencia de ese sentido de desorientación que ya hemos comentado en repetidas ocasiones. El comienzo del verso original pretende recrear una llamada de atención a un desconocido para pedirle directrices en su regreso a casa. Sin embargo, si tenemos en cuenta la finalidad comunicativa del poema, se podría traducir «Wait, Mister» por «Oiga, espere», ya que es la forma más común de detener a un extraño por la calle manteniendo la muestra de respeto social con la tercera persona formal del presente de singular.

T.O.: and the dark is moving in the corner.

T.M.: y la oscuridad se mueve en esta habitación. 
Por un lado, la cercanía con el original en "se mueve» consigue trasvasar la sonoridad del poema, pero dificulta la lectura del mismo, ya que sumada la sustitución de "corner» por «habitación», se recrea una imagen diversa. Aunque es cierto que no altera a la función principal del texto, la asimetría lingüística no impide trasvasar la carga semiótica y la imagen que Anne Sexton crea en lengua inglesa. En la versión original, la oscuridad no se mueve a través de la habitación, sino que se trata de una maraña inquieta situada en una de las esquinas, donde se proyecta la sombra por la luz de la luna que entra por la ventana y que se hace visible al apagar la luz. La personificación de la oscuridad transitando la habitación de la que habla no forma parte del escenario original. Recordemos no existe limitación de ritmo de cantidad, intensidad o timbre (Martínez, 2018), así que el traductor se podría haber servido de distintas estrategias para recrear la imagen. El verbo asentar podría ser una posible solución, ya que recoge esta idea de algo que flota o se mueve hasta quedar arrinconado, consiguiendo el mismo efecto visual en el lector meta.

T.O.: There are no sign posts in this room

T.M.: No hay indicadores en esta habitación

En esta ocasión, destaca el uso de la palabra «indicador» como traducción de «sign posts». Según el diccionario de la Real Academia de la Lengua Española (DRAE), indicador tiene como única acepción: «1. adj. Que indica o sirve para indicar». Es decir, este adjetivo acompaña al objeto que designa y cuya función es la de mostrar indicios o señales. En ningún momento se refiere a las señales de dirección presentes en los arcenes de las vías de circulación que muestran el camino que tenemos que tomar para alcanzar un destino. Podría parecer una variación dialectal ajena al español peninsular, pero si tenemos en cuenta el origen sevillano del traductor y que la antología se ha publicado en España, esta opción queda descartada. Sería más cómodo, más «natural» si cabe, traducir «sign posts» por «señales». Además, en el verso 26 «there are no signs to tell the way», se retoma la idea del principio del poema y en la traducción de Reina Palazón sí que decide cambiar «indicador» por «señal» para que no sea redundante con el verbo indicar: "y no hay señales que indiquen el camino»; perdiendo en la versión traducida la repetición del original.

T.O.: and everyone in here was crazy.

T.M.: y aquí cada uno estaba loco.

Everyone en inglés recoge a todos los miembros integrantes de un concepto. En la traducción se ha optado por un calco del plano formal de la 
palabra every/one y el resultado es "cada uno». Por regla general, y por equivalencia semántica, englobar o generalizar un colectivo bajo una misma idea se hace mediante el pronombre cuantificador todos.

\author{
T.O.: Music pours over the sense \\ and in a funny way \\ T.M.: La música se derrama sobre la sensación \\ y de una manera divertida
}

Los errores de traducción se deben a falsos sentidos causados por la incomprensión del original. Sense puede referirse a la «sensación» en cuanto perfección, a cualquiera de los cinco sentidos, pero también al «raciocinio». Teniendo en cuenta que Anne Sexton se balancea entre la razón y la demencia en estos versos, elegir la acepción más adecuada para no alterar la metáfora no debería plantear serias dificultades. Durante la estrofa, la poeta nos describe cómo la música va inundando su mente hasta tener mejor visión de la realidad que ella misma. El segundo error de traducción nace de la mala comprensión del adverbio funny, que no es «divertido», sino «extraño», «raro», como se recoge en la segunda acepción del MerriamWebster: «2: differing from the ordinary in a suspicious, perplexing, quaint, or eccentric way». Este falso sentido cobra especial gravedad respecto a las imprecisiones anteriores porque altera en alto grado el significado del poema.

\title{
T.O.: I have forgotten all the rest.
}

T.M.: He olvidado todo el resto.

Al igual que en casos anteriores, el traductor se mantiene muy ligado a la estructura del original, haciendo una traducción palabra por palabra. Si bien la traducción puede funcionar, el lector meta sabrá en todo momento que se encuentra ante una traducción porque la estructura es poco convencional en la L2. Frente a esta situación, tenemos la opción de mantener la sonoridad del original como bien hace Reina Palazón, pero quizá sea necesaria una reestructuración de la oración: «El resto lo he olvidado», creando incluso una rima interna como en el original. Otra opción, si queremos acercarnos a la naturalidad del lenguaje en la poesía de Anne Sexton, podría ser traducido como «He olvidado lo demás», más naturalizante para el contexto comunicativo que crea entre ella y su lector. Este fenómeno se repite en el siguiente ejemplo:

T.O.: just the radio beating to itself

T.M.: sólo la radio sonando para ella misma

Hikma 18 (1) (2019), 211 - 230 
Itself, en inglés, tiene un uso más extendido que su equivalente en español. Además de «destinatario» o «propiedad», la lengua inglesa recurre a ellos para explicitar «soledad» o «exclusividad». La traducción al español se hace dura a la vista y oído del destinatario. La imagen que se pretende crear es la de una radio que suena en algún lugar sin que nadie le preste atención, como un objeto de attrezzo acústico en la sala en que se encuentra la protagonista del poema. Trasladar esta descripción de la situación es posible, de manera quizá más efectiva, sustituyendo "para ella misma» por «sola».

T.O.: La, la, la, Oh music swims back to me

T.M.: La, la, la. La música vuelve hacia mí

La preposición hacia implica que la música se traslada en dirección a ella, un traslado físico. Sin embargo, lo que nos pretende evocar es cómo la música vuelve a su cabeza, como un recuerdo que se materializa con fuerza en el presente. A pesar de ser sinónimos en la mayoría de sus usos, la elección de a en lugar de hacía cambia ligeramente el significado, siendo más preciso en la descripción el primero. Si lo generalizamos, algo «se nos viene a la cabeza», en este caso, la música en el ondear acuoso de su memoria.

T.O.: The night I came I danced a circle

T.M.: La noche que vine dancé en círculo

En el traslado interlingüístico, «venir» podría sustituirse por «llegar», ya que no podemos olvidar que se detiene a narrar su llegada al centro psiquiátrico, y cuando nos referimos con la distancia temporal al momento en el que pisamos por primera vez un sitio, hablamos de «la llegada». Ahí la traducción se queda corta, deja al lector un poco perplejo por la elección del verbo. Así mismo, al traducir «dance» por «danzar» rompe con la repetición presente en el original a favor del plano fonético, una ruptura que supone la lejanía lingüística del lector con el texto, ya que danzar tiene unas connotaciones estilísticas distintas a bailar, cuyo uso está más restringido y no es común en la variedad peninsular.

- Errores de conjugación verbal y sintácticos:

Por otro lado, la obligación en inglés de comenzar la frase o especificar mediante el pronombre personal sujeto o complemento directo, no es de obligado traslado en español al tratarse de una lengua con una conjugación verbal completa y con formas asignadas a cada persona y número. No es 
necesario recurrir a ellos ni usarlos con frecuencia, pues se carga el texto de redundancias.

T.O.: They turned the lights out

T.M.: Ellos han apagado las luces

Al no tratarse de un sujeto concreto, podemos omitir el pronombre personal de tercera persona en la traducción, ya que queda claro, sin lugar a dudas, de que alguien ha apagado la luz y que no se ha apagado sola. Es una redundancia que rompe con el ritmo de lectura del poema y el estilo.

T.O.: Imagine it. A radio playing

T.M: Imagina esto. Una radio suena.

T.O.: I liked it and danced in a circle.

T.M.: Me gustaba eso y bailé en un círculo.

En ambos casos, el pronombre demostrativo con función de complemento directo puede ser suprimido en la L2. En el primer caso, porque el uso aislado del verbo ya encierra un significado completo. En el segundo, lo consideramos redundante porque en los versos precedentes describe la situación que «le gusta», así que se infiere sin necesidad del complemento directo a qué se refiere.

En lo que se refiere a la elección de verbos, «la radio suena» para romper el hilo expositivo del original: está narrando la acción del pasado mediante el uso del gerundio en inglés, que en español se traduciría por el pretérito imperfecto, tiempo usado, en general, para los pasajes descriptivos. Lo mismo sucede en el verso sucesivo: "I liked it and danced in a circle» / «Me gustaba eso y bailé en un círculo»; al tratarse de la descripción de una situación, el pretérito indefinido del verbo bailar debería sustituirse por el imperfecto, con el fin de mantener la exposición sin alteraciones de tiempo.

T.O.: I mean it remembers better;

T.M.: Quiero decir recuerda mejor;

La sintaxis del inglés no presenta ninguna anomalía, a diferencia del español. Se omite el nexo con función de relativo que, quedando una frase sintácticamente errónea que no se justifica en un juego de la autora en la lengua original. 
- Trasvase de metáforas e imágenes poéticas:

En la segunda estrofa del poema, la descripción de su primera noche entre los muros del psiquiátrico se metaforiza. La personificación de los elementos celestes los hace compañeros de viaje $y$, por ende, también comparten el sufrimiento de las adversidades ligadas a esa experiencia desagradable.

\section{T.O.: It was the stangled cold of November;}

Even the stars were strapped in the sky

T.M.: Era el frío cortante de noviembre; incluso las estrellas estaban abrochadas en el cielo

En esta parte del poema, la autora concentra la mayor carga poética y metafórica del texto. Ajeno a la imagen y la metáfora, el primer error lo encontramos en «It was», ya que es la forma impersonal en inglés para hablar de la climatología. En español, la temperatura también se expresa con una oración impersonal, pero introducida por el verbo hacer en tercera persona del singular. En el juego de imágenes que componen esta metáfora, la adjetivación común del frío es cortante, como se usa en el texto traducido, porque quema la cara y provoca grietas. Aquí el frío es tal que el tiritar le impide la respiración. Esta interpretación cobra sentido al ver que la poeta recurre a una serie de elementos aprisionadores en este binomio de versos y en el verso 25 - «They lock me in this chair at 8 a.m.»-, incomodando al lector al hacerle experimentar su sentimiento de agobio y asfixia. Así que se queda corto al traducir «strapped» por «abrochadas», por la carga positiva del broche, proyectando una sensación de que las estrellas decoraban la noche cuando la realidad es que ellas, como la protagonista de la noche, se encuentran envueltas en la misma oscuridad y amarradas para no poder huir y «estranguladas» por la situación.

T.O.: and that moon too bright

Forking through the bars to stick me

T.M.: y aquella luna demasiado brillante bifurcándose a través de los barrotes para hincarme

Junto al nombre del poema, aquí se encuentra quizá el mayor reto de traducción. To fork es la verbalización del sustantivo homónimo y significa «clavar un tenedor». El haz cegador de la luna atraviesa una ventana con barrotes y proyecta su luz bifurcada en forma de tenedor que posa sobre ella. El traductor ha optado por explicitar la metáfora dada la inexistencia de un verbo equivalente que mantenga la metáfora original en el plano formal. No

Hikma 18 (1) (2019), $211-230$ 
obstante, existe la posibilidad de recurrir a otras imágenes similares para resolver lo imposible del trasvase literal del verso dada la asimetría léxica entre estos pares de lenguas. Verbos como punzar o aguijonear transmiten la idea de clavar sobre la piel con el mismo movimiento angular del tenedor sobre la comida, compensando la pérdida, por ejemplo, dándole más dramatismo al adjetivo que acompañe a la luna del verso anterior.

\section{CONCLUSIONES}

Los resultados arrojados del análisis evidencian las diferencias estructurales en la proyección de imágenes entre el inglés y el español. Para poner de manifiesto de forma más clara los resultados cuantitativos, pasamos a resumirlos en el siguiente gráfico:

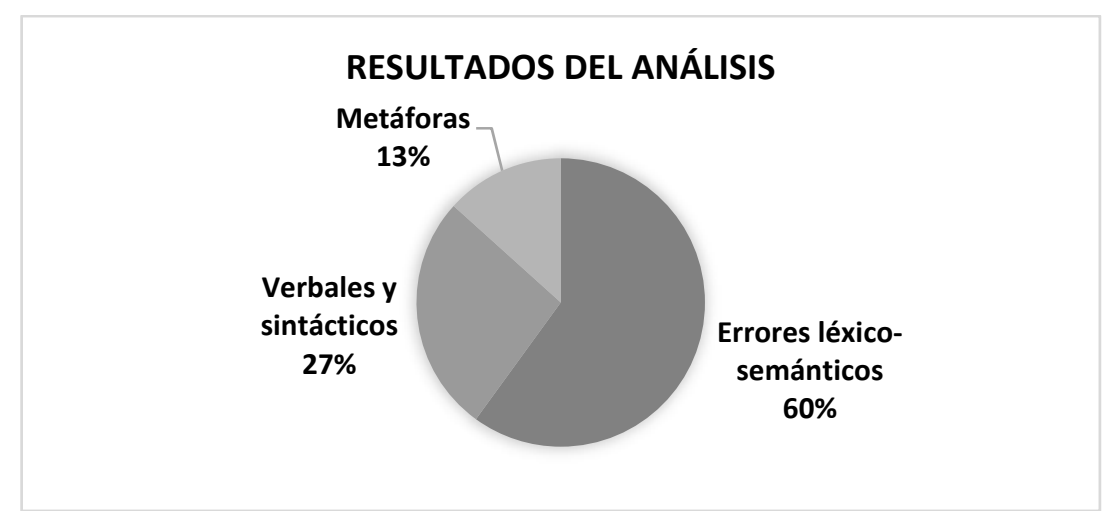

Comprobamos que, en el mayor número de los casos, los errores se deben a la mala interpretación del original y la desambiguación imprecisa de las palabras polisémicas. Este fallo de comprensión del original, sumado a la asimetría lingüística, pragmática y comunicativa entre el inglés y en español, requiere al traductor una competencia lingüística potente. El desglose de la carga poética y metafórica del TO es de crucial importancia; y es ahí donde entran en juego tanto el análisis filológico del texto como la documentación exhaustiva sobre la autora en cuestión. De esa forma, conseguimos alcanzar la carga connotativa escondida detrás de su estilo y el uso de la lengua, con el fin de recrearla en el TM y hacerla llegar al lector de la traducción.

Dichas diferencias entre los códigos lingüísticos y la semiótica de las culturas en las que se encuentran pueden abordarse desde una perspectiva pragmática-comunicativa que busque la recreación de los efectos, visto que 
el trasvase formal se queda corto y que supone la pérdida de la carga connotativa del poema. Dicho esto, ahondando en lo pragmático del género poético, no hay que descartar, en la medida de lo posible, la idea de mantener la estructura del original cuando no perjudique la comprensión del TM, pero sin recurrir en la totalidad de los casos a la traducción literal, como en el caso de José Luis Reina Palazón, quien recurre incluso a la traducción palabra por palabra en alguna ocasión.

El traductor que asuma la traducción de un texto poético, como señala Gallegos (2001: 89), debe tener como máxima y no olvidar que

El ideal de la traducción poética debe ser la recreación del poema original en la lengua de llegada tratando, por un lado, de tender la mayor fidelidad posible al texto origen y por otra, de servirse de los procedimientos poéticos y estilísticos de la propia lengua de llegada. El objetivo será siempre producir en el espíritu de los respectivos lectores —el de la lengua de partida y el de la de llegada- unas sensaciones o efectos análogos.

En el caso de «Music Swims Back to Me», recordemos que el poema se integra en una antología completa de la obra y, por ende, es nuestro deber romper una lanza a favor del traductor, porque a pesar de la libertad métrica y rítmica de la obra de Anne Sexton, el resultado final pudo verse condicionado por otros factores como los plazos de entrega, condiciones del encargo editorial o cambios impuestos por parte del revisor, que son ajenos a su trabajo. Sin embargo, consideramos que la traducción del poema priva al lector meta de la creación de imágenes y estilo proprio de Anne Sexton, rasgo más importante en su poesía y que se ha quedado en el camino un contenido que puede trasladarse a nuestra lengua recurriendo a distintas técnicas y estrategias de traducción. Dada las circunstancias, estimamos ineludible proponer una nueva versión del poema traducido que incluya las aportaciones de este estudio y los resultados del análisis comparativo y que se aleje de las limitaciones puramente lingüísticas en virtud de lo pragmático del acto comunicativo en el que se basa el poema.

\section{La música vuelve a mi}

Oiga, espere, ¿cuál es el camino a casa?

Han apagado las luces,

y la oscuridad se asienta en la esquina. No hay letreros en esta habitación, cuatro señoras, rondan los ochenta, cada una de ellas lleva un pañal.

Hikma 18 (1) (2019), $211-230$ 
La, la, la. Oh, la música vuelve a mí y puedo sentir la canción que pusieron

la noche que me dejaron

en esta institución privada de montaña.

Imagina. Una radio sonaba

y todos aquí estaban locos.

Me gustaba y bailaba haciendo círculos.

La música inunda la razón,

y de forma sospechosa

parece ver más que yo.

Quiero decir que recuerda mejor,

recuerda la primera noche aquí.

Hacía el frío estrangulador de noviembre,

hasta las estrellas estaban amarradas en el cielo;

y aquella luna cegadora

atravesaba los barrotes para aguijonearme

en la cabeza con un canto.

El resto lo he olvidado.

Me ataron a esta silla a las ocho de la mañana, y no hay señales que me indiquen el camino.

Solo la radio sonando sola

y la canción que recuerda

más que yo. Oh, la, la, la,

esta música vuelve a mí.

La noche que llegué bailé haciendo círculos y no estaba asustada.

¿Oiga? 


\section{REFERENCIAS BIBLIOGRÁFICAS}

Belotto, J. (2013). La didáctica de la traducción poética en el EEES. Estudios de traducción, 3, pp. 83-94. Disponible en: http://dx.doi.org/10.5209/rev_EST.2013.v3.41992 [Consultado el 06/02/2019].

Diccionario de la Real Academia de la Lengua Española, en línea. Fecha de consulta: [15/08/2018].

Etkind, E. (1982). Un Art enc rise: essai de poétique de la traducción poétique. Lausanne: L'Age d'Homme.

Fink, M. (1999). Electroshock: Restoring the Mind. Oxford, Estados Unidos: Oxford University Press.

Jakobson, R. (2000). On Linguistic Aspects of Translation. Venuti, L. (ed.), The Translation Studies Reader (pp. 113-118). London: Taylow \& Francis Group.

Gallegos, J.A. (2001). El capricho de la traducción poética. TRANS, 5, pp. 77 90.

Hurtado, A. (2004). Traducción y Traductología. Introducción a la Traductología. Madrid: Cátedra.

Martín, M. (2003). Discursividad sexual y poder disciplinario: una visión foucaultiana en la obra de tres poetas americanas. La Laguna, España: Servicio de publicaciones Universidad de la Laguna.

Martínez, B. (2018). La traducción poética: aproximación a la traducción del ritmo en la poesía de François Villon. Cédille, revista de estudios franceses, 14, pp. 303-321. Disponible en: http://cedille.webs.ull.es/14/13martinez.pdf [Consultado el 07/02/2019].

Merriam-Webster Dictionary, en línea. Fecha de consulta: [16/08/2018].

Middlebrook, D. (1998). Anne Sexton: una biografía. Barcelona, España: Circe. Traducido por Roser Berdagué.

Ramírez, T.J. (2009). Traducción de la metáfora poética desde un enfoque comunicativo: metáfora lorquiana. Las Palmas de Gran Canaria, España: Universidad de Las Palmas de Gran Canaria, Servicio de Publicaciones-Fundación Mapfre Guanarteme.

Samaniego, E. (1996). La traducción de la metáfora. Valladolid, España: Secretariado de Publicaciones e Intercambio Científico-Universidad de Valladolid. 
- (2002). Prescripción y descripción: la metáfora en los estudios de traducción. Trans, 6, pp. 47-61.

- (2011). Translation Studies and the Cognitive Theory of Metaphor. Review of Cognitive Linguistics, 9 (1), pp. 262-279. Disponible en: https://doi.org/10.1075/rcl.9.1.12sam [Consultado el 06/02/2019].

Sexton, A. (2013). Poesía completa. Oruense, España: Ediciones Linteo. Traducido por José Luis Reina Palazón.

Sexton, A. (1999). The Complete Poems. Boston, Estados Unidos: Houghton Mifflin Company.

Silvestre, A. (2008). La traducción poética, un reto posible en Actas del simposio internacional de poesía española e hispanoamericana. Brasilia: Instituto Cervantes, pp. 130-140.

Soto, D. (2014). Bases para la traducción-recreación al español de poemas escritos en francés. ENTRECULTURAS, 6, pp. 89-114.

Vidal, A. (2005). En los límites de la traducción. Granada, España: Comares.

Yebra, V. (1994). Problemas de la traducción literaria. Eguíluz, F., Merino, R., Oslen, V. et al. (eds.), Transvases culturales: literatura, cine, traducción (pp. 9-21). Vitoria-Gasteiz, España: UPV/EHU. 